\title{
Urban electrical vehicles as the solution for public transportation in the cities of Romania
}

\author{
V. Rădulescu, I. Străinescu, L. Moroianu, E. Tudor, \\ S. Gheorghe \& C. Goia \\ R\&D Department of ICPE SAERP, Bucharest, Romania
}

\begin{abstract}
In the European Recommendation COM (2007) 551 final, we find that, in the European Union, over $60 \%$ of the population lives in urban areas. Urban areas now constitute the living environment of the majority of the population and increased traffic in town and city centers has resulted in chronic congestion. Every year nearly 100 billion Euros, or 1\% of the EU's GDP, are lost to the European economy as a result of this phenomenon.

The analysis of the means of transport presented here will show which electrical vehicle is the solution for non-polluting transport according to each specific need.

ICPE SAERP, together with RAT Bucharest, has modernized classic tramcars, equipping them with three-phase inverters and asynchronous motors and a partially lowered floor. By 2011, 18 tramcars will be modernized.

ICPE SAERP, together with ASTRA BUS Arad, produce and deliver in Bucharest new trolleybuses with lowered floors, equipped with three-phase inverters, with asynchronous motors and with converters for the auxiliary services and for the air conditioning system. Also the trolleybus has a protection device against high voltage present on the body of the vehicle, which is controlled by means of a DSP processor in the master controller.

The methodology used in our research is presented in this paper and the results that led us to the conclusions that the type of public transportation proposed is cleaner, more reliable, more efficient and more comfortable than others.
\end{abstract}

Keywords: light metro - LM, metro, tram, trolleybus, urban electric transport. 


\section{Introduction}

In the European Recommendation COM (2007) 551 final [1, 2], we find the following:

- In the European Union, over $60 \%$ of the population lives in urban areas. At least $85 \%$ of the EU's gross domestic product - GDP - is created in urban areas. Towns and cities are the drivers of the European economy.

- Urban areas now constitute the living environment of the majority of the population, and it is imperative that the quality of life in these areas should be as high as possible.

- Throughout Europe, increased traffic in town and city centers has resulted in chronic congestion, with the many adverse consequences that this entails in terms of delay and pollution. Every year nearly 100 billion Euros, or 1\% of the EU's GDP, are lost to the European economy as a result of this phenomenon.

- Air and noise pollution is getting worse every year. Urban traffic is responsible for $40 \%$ of $\mathrm{CO}_{2}$ emissions and $70 \%$ of emission of other pollutants arising from transport.

- The number of road traffic accidents in towns and cities is also growing each year: one in three fatal accidents now happen in urban areas and it is the most vulnerable people, namely pedestrian and cyclist, who are the main victims.

The main task of RATB (the Urban Transport Administration of Bucharest) is to ensure together with Metrorex (the subway administration of the city) passenger transportation in Bucharest and surroundings of the city. This desideratum is especially hard in the morning between 7-9 and afternoon 15-20, when the traffic reaches rush hour.

To ensure this kind of transportation in Bucharest and surroundings, RATB uses a network of $60 \mathrm{~km}$ with 3 Light Rail - LR, over $300 \mathrm{~km}$ tramcar lines with a park of almost 500 tramcars, 18 trolley bus lines with a park of 300 trolley buses and a bus park of 1300, and 1,42 million personal cars [3]. The transportation lines in Bucharest also depend on the 4 subway lines so that the transportation is improved.

During rush hours, the tram and trolley lines are most of the time obstructed by cars so the average transport speed is $8-10 \mathrm{~km} / \mathrm{h}$ for trams and $6-9 \mathrm{~km} / \mathrm{h}$ for trolley buses, and during the rest of the day average speeds are $10-14 \mathrm{~km} / \mathrm{h}$ for trams and $9-14 \mathrm{~km} / \mathrm{h}$ for trolley buses.

ICPE SAERP together with RAT Bucharest has modernized one classic tramcar, equipping it with three-phase inverters and asynchronous motors and a partially lowered floor. By 2011, 18 tramcars will be modernized.

ICPE SAERP together with ASTRA BUS Arad, produce and deliver in Bucharest new trolleybuses equipped with three-phase inverters and asynchronous motors and with lowered floor and the converters for the supplying the auxiliary services and the air conditioning system. Also the trolleybus has a protection device against high voltage present on the body of the vehicle, which is controlled by means of DSP processor on the master controller. 
Today the gases produced by automobiles and some abuses pollute Bucharest intensely and this happens also due to the few regulations in our country that allow running cars and buses, which emanate large quantities of polluting emissions well over the level allowed in Western Europe [4].

The impact on Bucharest's environment consists of the noise level that for 2007 was estimated at $62.8 \mathrm{~dB}$ and the emissions as follows: 2 tons $\mathrm{NO}_{\mathrm{x}} ; 10$ tons $\mathrm{CO} ; 1.2$ tons unburned hydrocarbons/particles; 357 tons $\mathrm{SO}_{2} ; 1.113$ tons $\mathrm{CO}_{2}$.

These pollutants exclusively come from transportation with private cars, autobuses and less from taxis.

The 2010 distribution of daily car trips in Bucharest:

\begin{tabular}{|c|c|c|}
\hline & ivate cars: & \\
\hline & On foot: & \\
\hline & By bus: & \\
\hline & By tramcar: & \\
\hline & By subway: & \\
\hline & By trolley bus: & \\
\hline- & By share taxi (minibuses) & \\
\hline & By taxi: & \\
\hline & Private autobuses: & \\
\hline
\end{tabular}

This paper presents the methodology used in our research and the results that led us to the conclusions that the type of public electric transportation proposed is cleaner, more reliable, more efficient and more comfortable than any other.

\section{The electrical vehicle transportation considered by ICPE SAERP is cleaner and non-polluting}

As shown above, Bucharest is one of the most polluted capitals in Europe. The pollution is caused mostly by private car transportation $-25 \%$ of passenger transport, contributing almost $90 \%$ to the pollution of the city. This happens because over $70 \%$ are used cars; old and polluting.

Autobuses take $17 \%$ of passenger transport, contributing some $9 \%$ to the pollution of the city. These are still necessary to ensure a civilized transport especially in areas where tramcar, subway or trolley bus transportation demands high initial investments and long implementing periods.

ICPE SAERP took these observations into account and decided to assimilate some equipment:

- The assimilation of equipment to modernize the existing RATB tramcars; in collaboration with RATB, ICPE carried out electrical frames for light metroLM and tramcars, using hierarchical commands: to control the train, the coach, each bogie and to drive using three-phase inverters and asynchronous traction motors.

- Assimilating equipment to drive the solo and articulated trolleybuses produced by Astra Bus Arad. More than 300 chopper and three-phase inverters driving equipment and 30 asynchronous traction c.c. motors with command according to the stator field have been delivered. 
- Plans to assimilate in the near future new driving equipment for electric autobuses meant for passenger and cargo transport.

Taking into account that the use of electric vehicles does not directly cause pollution and the existing autobuses do not have a great influence in city pollution, the need for reduction in private car use in Bucharest arises. The number of private cars used for passenger transport stands today at 1.4 million. In the next 5 years it is desired that half the pollution from passenger transport vehicles should be reduced.

\section{Improving the efficiency of electric vehicles transport}

\subsection{General approach about electric transport system}

Although the public transport network is fairly developed in Bucharest (similarly all the great cities in Romania) the transport time is relatively long. The average

Table 1: $\quad$ Public transport options and key characteristics.

\begin{tabular}{|c|c|c|c|c|}
\hline & Bus ways & $\begin{array}{c}\text { Light } \\
\text { Metro } \\
- \\
\text { Tramways } \\
\end{array}$ & Metro & $\begin{array}{c}\text { Suburban } \\
\text { Rail }\end{array}$ \\
\hline $\begin{array}{c}\text { Current } \\
\text { Applications }\end{array}$ & $\begin{array}{c}\text { Widespread } \\
\text { in } \\
\text { Latin } \\
\text { America }\end{array}$ & $\begin{array}{l}\text { Widespread } \\
\text { in Europe } \\
\text { Few in } \\
\text { developing } \\
\text { cities, none } \\
\text { with "high } \\
\text { ridership" }\end{array}$ & $\begin{array}{c}\text { Widespread, } \\
\text { mainly in } \\
\text { Europe and } \\
\text { North } \\
\text { America }\end{array}$ & $\begin{array}{c}\text { Widespread, } \\
\text { mainly } \\
\text { in Europe } \\
\text { and North } \\
\text { America }\end{array}$ \\
\hline Flexibility & $\begin{array}{c}\text { Flexible, } \\
\text { robust } \\
\text { operationally }\end{array}$ & $\begin{array}{l}\text { Flexibility, } \\
\text { risky in } \\
\text { financial } \\
\text { terms }\end{array}$ & $\begin{array}{l}\text { Inflexible } \\
\text { and risky in } \\
\text { financial } \\
\text { terms }\end{array}$ & Inflexible \\
\hline $\begin{array}{c}\text { Initial Cost in } \\
€ \mathbf{m} / \mathbf{k m}\end{array}$ & $1-5$ & $\begin{array}{l}10-30 \\
15-30 \text { at } \\
\text { grade } \\
30-75 \\
\text { elevated }\end{array}$ & $\begin{array}{c}\text { 60-180 } \\
\text { underground }\end{array}$ & \\
\hline $\begin{array}{c}\text { Practical } \\
\text { Capacity in } \\
\text { Pass/hr/direction }\end{array}$ & $10-20,000$ & $10-12,000$ & $60,000-+$ & 30,000 \\
\hline $\begin{array}{c}\text { Operating Speed } \\
\text { In } \mathrm{Km} / \mathrm{hr}\end{array}$ & $17-20$ & $15-25$ & $30-40$ & $40-50+$ \\
\hline Level of service & Quite good & Good & High & $\begin{array}{c}\text { Varies, few } \\
\text { Infrequent } \\
\text { station }\end{array}$ \\
\hline
\end{tabular}


distance from place of residence respectively place of work to the first urban transport station (including subway stations) is $470 \mathrm{~m}$ (10 $\mathrm{min}$ on foot) in central areas and $760 \mathrm{~m}$ (17 min on foot) in the outskirts.

The long transport time is due to the large number of private cars that cause terrible traffic in the city. If the subway and light metro transportation are not affected by car traffic, the tramcars, autobuses and trolley bus are affected to a great extent.

The speed ranges for the urban electrical transport in Bucharest presents for rush hours (7-10, respectively $15-21)$; the average speed is $1-7 \mathrm{~km} / \mathrm{h}$ for trolley buses and $3-10 \mathrm{~km} / \mathrm{h}$ for tramcars, because the access streets are blocked by cars [6].

Table 1 presents a summary of the transport efficiency analysis according to different transportation means [7].

To reduce transport time with electric transport means i.e. tramcars, trolley buses and electric autobuses, the City Hall must employ European Structural Funds to [7]:

- Transform some main tramcar lines in lines for electrical frame light metroLM (including blocking the access of other vehicles on the line and building longer passenger refuges for longer trains with 2-3 coaches) and surrounding the existing tramcar lines with fences to prevent the access of cars, trucks and auto buses.

- Restricting car access on main streets in the central area of the city, using different methods, to ensure a greater commercial speed for trolley buses.

\subsection{Original and innovative solutions provided by ICPE SAERP regarding electric transport vehicles}

In order to increase the electric vehicle urban transport efficiency, ICPE SAERP has collaborated with RATB (URAC Section) and Astra Bus Arad to participate in modernization of the electrical vehicle transport park in Bucharest, other great cities in Romania and even in Sofia, the capital of Bulgaria. The innovative contribution consists of modernizing and assimilating the traction equipment and auxiliary services and air conditioning supply converters on the vehicles:

- $\quad$ The power diagram is simple, using traction standard devices, with clear destination, ensuring a long term maintenance of the equipment;

- The control diagram is dedicated to each type of traction equipment, using our own developed control boards type MBB (Motion Base Board). Those boards are particularly designed to fulfill all the requirements of traction equipments;

- $\quad$ The modular design will reduce the set-up and the maintenance operations in the workshop, as all the parts can be easily accessed;

- $\quad$ The placement of the equipment will use better cooling conditions and will have shorter cabling ducts. Also noise level is reduced for the equipment placed on the roof of the vehicle; 
- The control software of the traction converter is performing smooth movement of the vehicle, without shocks or vibrations. The vehicle is stopped using electric brake down to standstill without any jerking;

- The control software of the vehicle is performing a balance between the traction units in case of low adherence on the rail, meanwhile the load on the motors and converters is fairly shared;

- The maintenance activities are simple and must be performed twice a year;

- Diagnose software is developed in the house and is particularly designed for each type of equipment or vehicle. The software can be improved according to the customer's requirements.

\subsection{Applied research: a modernized tramcar as light rail vehicle}

As a solution for the city of Bucharest, where most of the rail tracks were renewed between 2005 and 2009, and where some tracks are separated from the road traffic, an old-fashioned tram was modernized by replacing the traction system with a new one, with two IGBT inverters and two asynchronous motors, control unit with microprocessor, wide-screen display for vehicle status and fault-event diagnose.

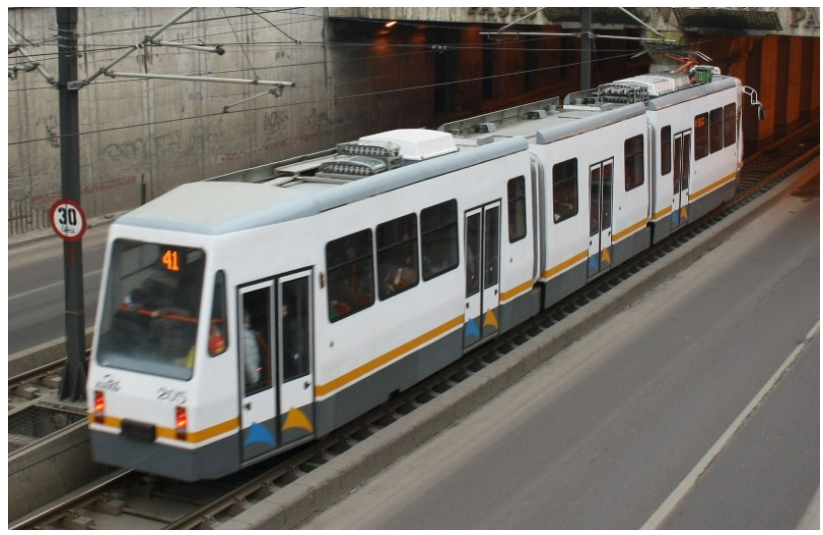

Figure 1: The tram with inverters located on the roof.

The power converters were placed on the roof, and the cables were using the old cable ducts of the tram. The driver's desk was equipped with a large screen display. The tram becomes lighter with more than 1,5 ton, and the connection and the cables are reduced with $30 \%$.

The control diagram of the tram is designed on the three-level architecture with capability of operation on train with 2 vehicles, for light-metro use.

\subsection{Control system for reliable $\mathrm{AC}$ drives on urban traction vehicles}

To perform a modern control for AC drives for electrical vehicle like trolleybus and trams is necessary to use a well adapted DSP platform which must support 
multiple interfaces necessary to connect and control different plug and play devices. This DSP platform must be reliable and also to have enough memory capabilities to implement a black-box system characteristic in order to put at the operator's disposal the main events selected by the user.

Concerning this, the DSP must have an internal flash code memory, internal RAM, multiple UARTs and CAN controller. In the following figure it will be presented the main architecture diagram for such a DSP core to control the vehicle.

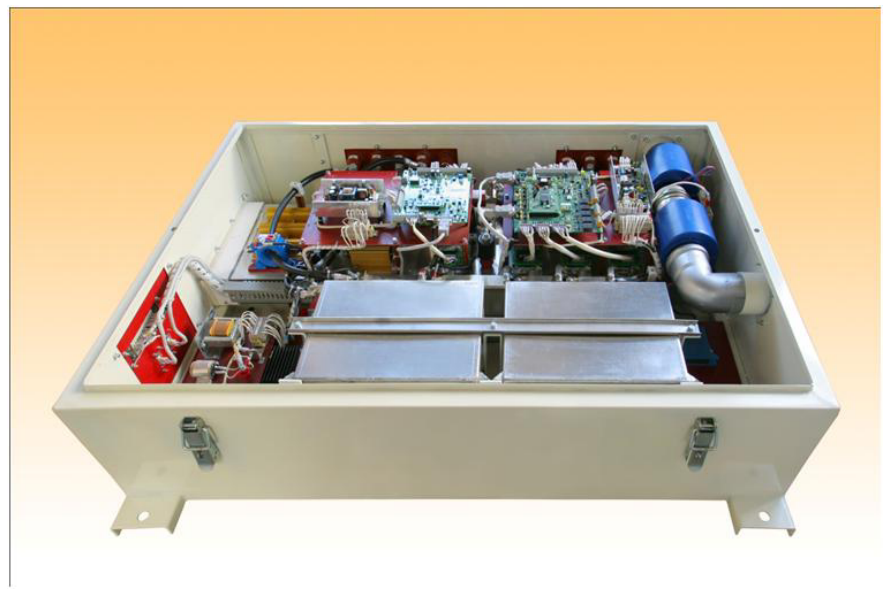

Figure 2: Traction inverter for tram.

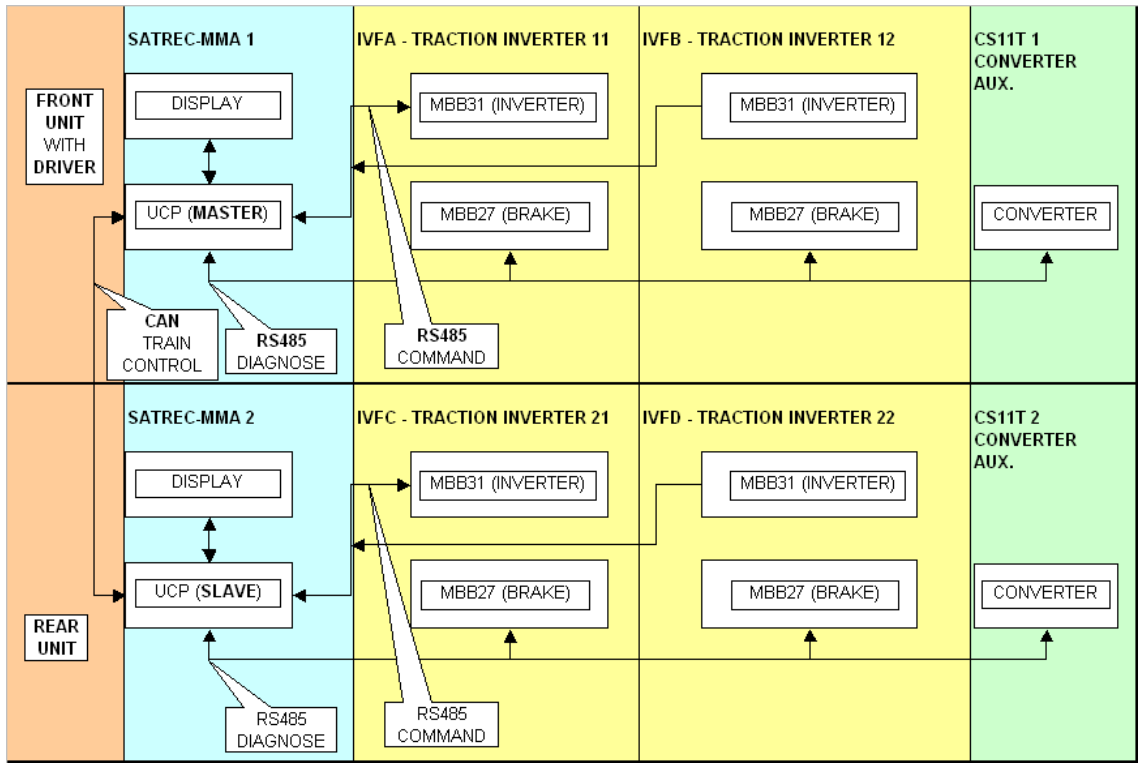

Figure 3: $\quad$ Light metro - the connection of the control units for two trams. 
For the development a Silicon Laboratories microcontroller C8051F040 was used which has a JTAG interface necessary for programming the flash code memory or for software maintenance.

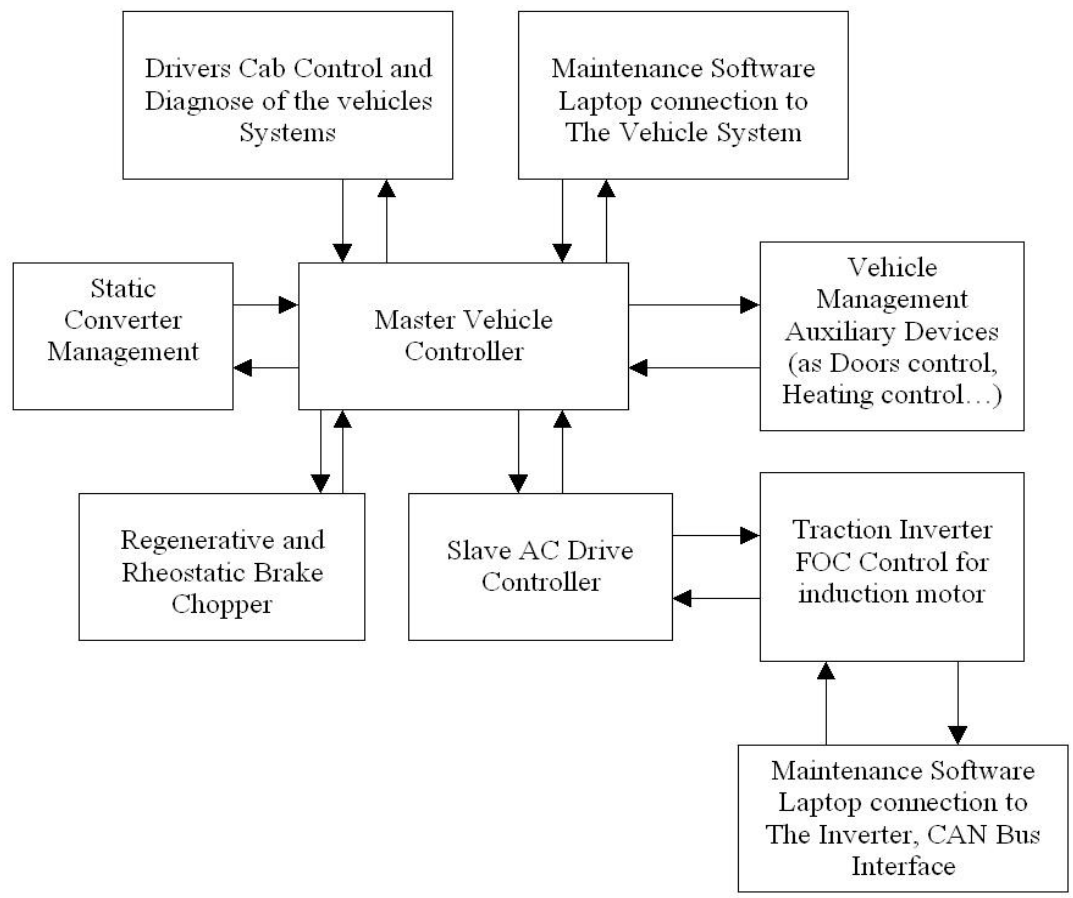

Figure 4: The block diagram for effective control for the traction.

During a complete circuit, the tram and the trolley bus meet different sections and intersections with other high voltage lines. This makes the supply voltage drop, for different periods of time that can stop the electrical equipment of the tram. The longest intersections are 4-5 m.

The current shocks absorbed by the contact line, due to the restart of the internal equipment that stop in these sections, determine a harsh demand on the supply network and can lead to the line's and the other electrical equipment's deterioration.

For the static source we want to avoid these stops and restarts in these sections from the circuit. Using the supercapacitors as short-term energy sources represents a solution for this problem.

Because the supercapacitors are made at a rated voltage of $2-2,5 \mathrm{Vcc}$, to function at high voltages we need to connect them in series-parallel.

For the supercapacitors calculation, we consider the following data:

- The rated power of the auxiliary services source: $12 \mathrm{~kW}$;

- Maximum intersection: $5 \mathrm{~m}$;

- Tram's speed: $7 \mathrm{~km} / \mathrm{h}$;

- Maximum time for passing through the no-supply line section: $3 \mathrm{~s}$. 
The energy demanded by the static source during the time it is not supplied by the contact line is:

$$
W_{u}=P * t=12.000 * 3=36.000[\mathrm{~J}]
$$

The variation at the supercapacitor's terminals is selected as $300 \mathrm{~V}$. The value of the supercapacitor battery is of $0,17 \mathrm{~F}$. Around 480 pieces will be connected in series, so the initial value of the supercapacitor will be $80 \mathrm{~F}$. In practice, the Maxwell Technologies, PC100E supercapacitor has been selected, having $\mathrm{C}=100$ $\mathrm{F}, \mathrm{V}=2,5 \mathrm{~V}, \mathrm{R}=0,013 \Omega$.

\section{The electric transport vehicles must increase comfort}

Concerning the comfort/accessibility issue, these attributes refer to the relative comfort of passengers. These attributes include stop and vehicle amenities (controlled temperature inside vehicle, transport quality, type of seating, access to information, ease of fare payment, access, security, cleanliness, etc) [5].

Passenger comfort has been neglected in Romania for a long time in the case of urban transport vehicles: subway, tramcars, trolley buses and autobuses. This is the reason why a lot of problems arise especially in the summer and wintertime in Bucharest and other cities in the country, when the temperature inside the transport vehicles is unbearable. At present, ICPE SAERP has assimilated converters and control blocks for the air conditioning equipment on tramcars and trolley buses, to control the temperature inside the vehicle according to European standards [8].

Except for the subway trains and light metro, most of the time the passenger travel standing due to the terrible traffic on the streets. To resolve this issue, ICPE SAERP continues to sustain the transformation of tramcar lines into light metro tracks, allowing more trains to run [6].

All the trolley buses that run in Bucharest are equipped with sound and visual systems to inform the passengers. Similar equipment will be mounted on tramcars and light metro trains.

To pay for the urban transport in Bucharest, the passengers use magnetic cards with a limited number of rides or monthly bus passes. Some cards can be used on the subway trains as well, through a convention between RATB and METROREX.

\section{Conclusions}

ICPE SAERP together with RAT Bucharest has modernized classic tramcars, equipping them with three-phase inverters and asynchronous motors and a partially lowered floor. By 2011, 18 tramcars will be modernized. The refurbishment operations for the old trams consist of:

- The modification of the body of the old vehicle to partial low-floor;

- The possibility to connect several trams into light metro trains which means that beside the tram control there is a superior control level that permit the full control of the train from the first tram; 
- The technical solution for the driving system will be exchanged from the classical mechanical controller with resistors steps to modern AC Drive for traction with induction motors and three-phase inverters in Field Oriented Control (FOC);

- All the commands, control and diagnosis of the tram's main driving system and auxiliary services will be performed by microprocessors type DSP (Digital Signal Processors);

- For the passenger comfort the habitacle will have an air conditioning system;

- For the real time information of the passengers will be added informational video and acoustic systems;

- ICPE SAERP together with ASTRA BUS Arad, produce and deliver in Bucharest new trolleybuses equipped with three-phase inverters and asynchronous motors and with lowered floor and the converters for the supplying the auxiliary services and the air conditioning system. Also the trolleybus has a protection device against high voltage present on the body of the vehicle, which is controlled by means of a DSP processor on the master controller.

To pay for the urban transport in Bucharest, the passengers use magnetic cards with limited number of rides or monthly bus passes. Some cards can be used on the subway trains as well, through a convention between RATB and METROREX.

\section{References}

[1] Green Paper. Towards a new culture for urban mobility. Commission of the European Communities. Brussels, 25.9.2007COM 551 Final.

[2] EEA Report Transport at cross roads - 2009 TERM 2008: Indicators tracking transport and environment in the European Union

[3] Master Plan for Urban Transport in Bucharest. 15.04.2008, General Counsel of Bucharest.

[4] National Inventory Report of Romania 2009 v. 1 National Environmental Protection Agency

[5] Hubell J., Wirasinghe S.C., McKendrick N., Morgan D., Mode succession in a public transit corridor, Urban Transport XV -2009, WIT Press.

[6] Străinescu I, Rădulescu V., The Need for Change of the Transport Mode in the Great Cities of Romania. Urban Transport XVI Conference, Pisa, 2011

[7] Technical Assistance for the Elaboration of the General Transport Master Plan. Second pool Master Plan. Reference MT: ISPA 2004/RO/16/P/PA/001/02, European Commission Brussels, Belgium

[8] Heating, ventilation and air conditioning in coaches. Code UIC 553 OR, 2003. 